\title{
MINI-REVIEW
}

\section{White Matter Lesions in Migraine}

Katharina Eikermann-Haerter* and Susie Y. Huang ${ }^{\dagger}$

From the Department of Radiology, * Massachusetts General Hospital, Harvard Medical School, Boston, Massachusetts; the Athinoula A. Martinos Center for Biomedical Imaging, ${ }^{\dagger}$ Department of Radiology, Massachusetts General Hospital, Harvard Medical School, Boston, Massachusetts; and the Harvard-MIT Division of Health Sciences and Technology, Massachusetts Institute of Technology, Cambridge, Massachusetts

\author{
Accepted for publication \\ February 12, 2021. \\ Address correspondence to \\ Katharina Eikermann-Haerter, \\ M.D., Department of Radi- \\ ology, Massachusetts General \\ Hospital, Harvard Medical \\ School, 55 Fruit St., Boston, \\ MA 02114. E-mail: khaerter@ \\ mgh.harvard.edu.
}

\begin{abstract}
Migraine, the third most common disease worldwide, is a well-known independent risk factor for subclinical focal deep white matter lesions (WMLs), even in young and otherwise healthy individuals with no cardiovascular risk factors. These WMLs are more commonly seen in migraine patients with transient neurologic symptoms preceding their headaches, the so-called aura, and those with a high attack frequency. The pathophysiology of migraine-related deep white matter hyperintensities remains poorly understood despite their prevalence. Characteristic differences in their distribution compared with those of common periventricular WMLs in the elderly suggest a different underlying mechanism. Both ischemic and inflammatory mechanisms have been proposed, as there is increased cerebral vulnerability to ischemia in migraineurs, whereas there is also evidence of blood-brain barrier disruption with associated release of proinflammatory substances during migraine attacks. An enhanced susceptibility to spreading depolarization, the electrophysiological event underlying migraine, may be the mechanism that causes repetitive episodes of cerebral hypoperfusion and neuroinflammation during migraine attacks. WMLs can negatively affect both physical and cognitive function, underscoring the public health importance of migraine, and suggesting that migraine is an important contributor to neurologic deficits in the general population. (Am J Pathol 2021, 191: 1955-1962; https://doi.org/10.1016/j.ajpath.2021.02.007)
\end{abstract}

Migraine is one of the most common neurologic disorders and is the third most common disease worldwide. It is characterized by throbbing/pulsatile unilateral headaches that last for 4 to 72 hours. Thirty percent of patients with migraine develop transient neurologic symptoms in the setting of an attack, the so-called migraine aura. Aura symptoms characteristically precede or overlap with the headache phase. The most common types of migraine aura involve visual impairment, followed by sensory, language, or motor symptoms. ${ }^{1}$

Neuroimaging studies have identified a twofold to fourfold increased incidence of white matter hyperintensities suggestive of white matter lesions (WMLs) in migraineurs compared with control subjects. ${ }^{2-7}$ WMLs are focal lesions without associated mass effect within the deep, subcortical, periventricular, or infratentorial white matter. ${ }^{3,8-11}$ WMLs are typically seen on T2 and fluid-attenuated inversion recovery sequences, and are believed to occur due to gliosis, demyelination, and/or loss of axons, possibly resulting from microvascular damage. ${ }^{12}$ WMLs exhibit a negative effect on both physical and cognitive function in older adults. ${ }^{13-15}$ If this association also holds true for lesions that develop as a consequence of migraine, migraine may be a major contributor to neurologic deficits in the general population. Therefore, better characterization and understanding of the etiology of WMLs in migraineurs are important, with possible implications for the management and treatment of migraine.

\footnotetext{
Funded in part by the Massachusetts General Hospital (Schlaeger Award, K.E.-H.).

Disclosures: None declared.

This article is part of a review series on small blood vessel disease in the brain addressing current knowledge, new mechanisms, biomarkers, and therapeutic approaches.
} 


\section{WMLs in Migraineurs and Their Implications}

Age and hypertension are well-known risk factors for common periventricular WMLs in the elderly that are presumably caused by increased interstitial fluid and altered periventricular fluid dynamics. ${ }^{16-18}$ In contrast, migraine is mostly associated with deep WMLs ${ }^{9,10}$ that present as early as in childhood migraineurs. In fact, WMLs are found in $10 \%$ of pediatric patients with migraine. ${ }^{19}$ However, in pediatric patients with migraine with or without aura,WMLs are not more prevalent than in control subjects and that no silent infarct-like lesions are identified. ${ }^{20}$ Interestingly, associations between migraine and WMLs are stable over time, suggesting that they occur earlier in life. ${ }^{7}$ In the Cerebral Abnormalities in Migraine, an Epidemiological Risk Analysis (CAMERA) population-based study sample of 30- to 60-year-old Dutch adults, female patients with migraine, were at increased risk of high deep WML-load (top 20th percentile), independent of migraine subtype and risk factors (odds ratio, 2.0; 95\% CI, 1.0-4.2). This risk was higher in those with high attack frequency (odds ratio, 2.6; 95\% CI, 1.2-6.0), suggestive of a causal relationship. Concurrent smoking, hypertension, and long-term oral contraceptive use further increased the risk. ${ }^{10}$ A follow-up investigation using the same study population showed that hyperintense lesions are predominantly located in the brainstem and cerebellar vascular border zone. WMLs are more commonly seen in patients with migraine with aura than those without aura and in those with a high attack frequency. Again, cardiovascular risk factors are not more prevalent in migraineurs with WMLs. Notably, progression of WMLs in individuals with migraine is not associated with migraine attack frequency, duration, severity, or antimigraine treatments. $^{21}$

Another longitudinal magnetic resonance spectroscopy study showed evidence of progression of migraine-related WMLs over time, with signs of more severe axonal loss and glial hypocellularity, as well as decreased intracellular energy production within a 3 -year period. ${ }^{22}$ The number of newly developed T2 hyperintensities exceeded the number of disappeared ones, further suggesting a progression of disease.

In contrast, the Epidemiology of Vascular Aging (EVA) study, a population-based, cross-sectional study in 780 elderly participants (mean age, 69 years), showed that migraine with aura is strongly associated with the cumulative volume of hyperintense lesions predominantly outside the cerebellum and brainstem. ${ }^{9}$ Another study found that the number of WMLs also increased with the intensity of nausea and disability during attacks. ${ }^{23}$ In contrast, a population-based sample of female twins aged 30 to 60 years identified through the Danish Twin Registry showed no association between silent brain infarcts, WMLs, and migraine with aura. ${ }^{6}$ The discrepancies between these studies might be related to different study designs (population versus hospital-based; prospective versus retrospective), characteristics of the participants (age, sex, headache or aura frequency, and conventional vascular risk factors), ascertainment of diagnosis (diagnosed by physician interview versus self-report), and neuroimaging methods (in particular lack of standardization, such as high versus low magnetic field, scanner type, and selection of sequences or slice thickness). It is important to also note that the sensitivity to detect WMLs using 1.5- or 3-T magnetic resonance imaging (MRI) may be higher than the sensitivity to detect cortical lesions. $^{24}$

The common periventricular WMLs in elderly nonmigraineurs are known to be associated with an increased risk of stroke, dementia, and cognitive decline. With respect to migraine patients, it is still not entirely clear whether deep WMLs have negative long-term functional consequences. In migraineurs, cerebral WMLs, but not subclinical infarcts or infratentorial lesions, are independently associated with syncope and orthostatic intolerance. ${ }^{25}$ There is no association between autonomic nervous system symptoms and the severity of migraine or migraine subtype. Cardiovascular measurements do not differ significantly between migraineurs and control subjects. ${ }^{21}$ The CAMERA-2 study found no association between deep WML load and change in cognitive scores. In addition, longitudinal studies show no evidence of an association between a history of migraine and an increased risk of dementia. ${ }^{8}$ This is in agreement with a prospective study by Rist et al, ${ }^{26}$ which found no link between cognitive changes and WMLs in migraineurs. In fact, in some studies, better cognition was noted in migraineurs. $^{27-29}$ The effect of WMLs on the clinical course of migraine is also not entirely clear. One study showed more frequent baseline WMLs in patients who did not report an improvement in migraine frequency after 3 years. 30

\section{Advanced MRI of White Matter in Migraineurs}

A variety of advanced MRI techniques have been applied to characterize the microstructural substrate of WMLs in migraineurs. Magnetization transfer imaging is a myelinsensitive imaging technique that indirectly quantifies the myelin content of white matter through the exchange of free water protons with bound water protons attached to macromolecules such as proteins or lipids. ${ }^{31}$ The magnetization transfer ratio (MTR) measures the amount of magnetization exchanged between the free and macromolecular-bound water protons, such that a ratio can be estimated from the signal intensities. MTR is lower in the presence of demyelination, and it may also be influenced by the elevated water content in tissues as a result of inflammation or edema as well as changes in axonal density. ${ }^{32}$ Several studies using magnetization transfer imaging in patients with migraine have suggested the presence of migraine-related focal microstructural damage. ${ }^{3,34}$ However, other studies found 
no significant differences in MTR in the whole brain and normal-appearing white matter in migraineurs compared with control subjects. ${ }^{35,36}$ A recent study of participants from the CAMERA-1 and CAMERA-2 studies examined whether visible WMLs exhibited alterations in MTR values compared with baseline MTR measurements in the normalappearing white matter on prior imaging, before the appearance of these lesions. ${ }^{36}$ The normal-appearing white matter that later progressed to WMLs at 9-year follow-up had a lower mean MTR at baseline compared with the contralateral white matter, suggesting that occult changes in microstructural tissue integrity may precede the development of frank WMLs on conventional T2-weighted MRI.

Diffusion-weighted imaging uses the Brownian motion of water molecules as a probe of brain tissue microstructure and has been applied to study white matter integrity in migraine. Diffusion tensor imaging models the diffusive motion of water as a tensor and offers several quantitative metrics for characterizing tissue microstructure: fractional anisotropy, mean diffusivity, axial diffusivity, and radial diffusivity. Diffusion tensor imaging studies have revealed decreased fractional anisotropy and increased mean diffusivity, indicating altered white matter integrity in the corpus callosum, ${ }^{37,38}$ optic radiations, ${ }^{39}$ and corticospinal tracts. ${ }^{40}$ A recent study reported a bilateral volume decrease in the occipital white matter adjacent to visual processing cortical areas not co-localizing with WMLs. ${ }^{41}$ Previous diffusion tensor imaging studies showed decreased fractional anisotropy in white matter tracts in the visual processing pathway, including the middle temporal region ${ }^{42}$ and optic radiations of participants with migraine, ${ }^{39}$ possibly due to increased axonal diameter as a manifestation of experience-dependent structural plasticity. However, decreased white matter volume makes less myelination due to abnormal maturation or axonal loss a more likely explanation. ${ }^{41}$

\section{Ischemia as a Possible Mechanism Underlying WMLs in Migraineurs}

The pathophysiological mechanisms leading to the development of WMLs in migraine and the histopathologic correlates of migraine-related WMLs are not fully understood. The proposed etiologic mechanism underlying WMLs includes ischemic microvascular disturbances with subsequent focal hypoperfusion of the cerebral parenchyma. ${ }^{43}$ In fact, reduced cerebrovascular reactivity to carbon dioxide precedes the development of WMLs in normal individuals without migraine. ${ }^{44}$ Decreased cerebral perfusion pressure/ sluggish cerebral blood flow has been observed during and after migraine attacks. ${ }^{45-47} \mathrm{~A}$ decrease in cerebral perfusion pressure during migraine attacks impairs the clearance of embolic particles, and occlusive thrombi further reduce blood flow. ${ }^{48}$ In fact, there is support for impaired cerebrovascular reactivity/autoregulation in migraine patients with WMLs, with evidence of increased levels of the vasoconstrictive nitric oxide synthase inhibitor asymmetric dimethylarginine in migraine patients with WMLs compared with those without WMLs and healthy control subjects. ${ }^{49}$ Because deep cerebellar territories, which are areas of predilection for migraine-related hyperintensities, have a pattern of progressively tapering arteries with only few anastomotic networks, these anatomic locations seem particularly vulnerable to hypoperfusion-related border zone ischemic lesion formation. ${ }^{50}$

Multiple factors support the assumption of episodic ischemia underlying or contributing to WMLs in migraineurs. First, migraineurs seem to be prone to cerebrovascular clot formation, with reported evidence of endothelial dysfunction, ${ }^{51,52}$ an increased incidence of hypercoagulability, ${ }^{53}$ and atrial fibrillation. ${ }^{54}$ Evidence for an important role of endothelial dysfunction in the generation of spreading depolarization (SD) and migraine comes from the observation that the potent vasoconstrictor endothelin-1, the strongest SD trigger in rodents in vivo, cannot cross the blood-brain barrier and only acts when secreted by endothelial cells abluminally via binding to receptors located on vascular smooth muscle and pericytes. ${ }^{55}$ Accordingly, intravascular endothelin-1 administration does not induce aura symptoms. ${ }^{56,57}$ Reactive narrowing of the arterial lumen and endothelial abnormalities stimulates thrombus formation. As a potential path for cerebral microembolism, an increased incidence of persistent foramen ovale has been reported in migraineurs. ${ }^{58}$ Second, the extent of WMLs in migraineurs correlates with reduced cerebrovascular reactivity in response to carbon dioxide. ${ }^{59}$ Hypoperfusion during migraine attacks may lead to delayed vascular restoration and predispose patients to subclinical or clinical ischemia, as well as the development of WMLs, in the setting of a reduced cerebrovascular response. Interestingly, the use of vasoactive medications is positively correlated with better cerebrovascular response, suggesting that vasoactive medications and the effective acute control of headaches might protect vascular function. In contrast, no association between cerebral vasodilatory dysfunction and WML load is observed in control subjects.

There is also evidence for migraineurs being prone to increased vasoconstriction in the interictal phase. ${ }^{60} \mathrm{At}$ resting state, there is evidence for mild vasoconstriction of cerebral arterioles in migraineurs, as suggested by a prolonged time delay between the R-wave of an ECG and the arterial pulse wave of cerebral microcirculation when measured by transcranial near-infrared spectroscopy. ${ }^{61}$ In addition, migraineurs exhibit diminished reactive arterial vasodilation, as evidenced by a decreased cyclic guanosine monophosphate and hemodynamic response to nitric oxide. ${ }^{62}$ Another study describes systemic arterial stiffness, lower carotid pulsatility index, and systolic blood pressure as being associated with WML load in migraineurs. ${ }^{63}$ During a migraine attack, vasospasm and hypoperfusion homolateral to the side of pain have been shown with MRI. ${ }^{64}$ One study reports that the dominant side of WMLs 


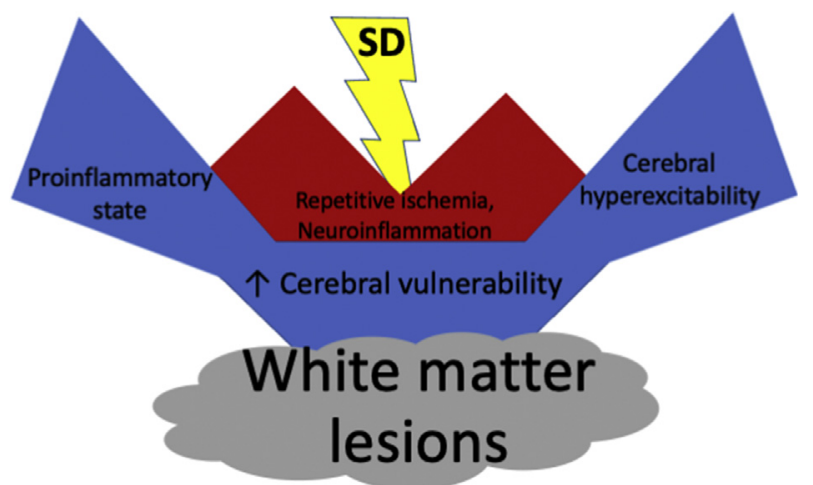

Figure 1 In migraineurs, there is evidence for cerebral hyperexcitability and a proinflammatory state at baseline, both of which may increase cerebral vulnerability (blue). SD during migraine attacks causes episodic ischemia and neuroinflammation, which may lead to cumulative damage over time in the vulnerable brain, contributing to the development of white matter lesions.

matched with the dominant side of headache. ${ }^{65}$ These findings suggest cerebral and systemic vascular dysfunction possibly causing relative cerebral ischemia in the setting of an impaired vasodilatory response, in case of an increase in cerebral metabolic demand. Third, the brains of migraineurs seem particularly vulnerable to ischemia. Cerebral blood flow required for tissue survival seems higher in migrainesusceptible brains, leading to infarction with milder ischemia.

Mutant mouse models of migraine develop larger and more rapidly expanding cerebral infarcts compared with their wildtype littermates ${ }^{66}$ while acute stroke patients with a migraine history show accelerated infarct growth with less potentially salvageable brain tissue/penumbra. ${ }^{67,68}$ As the proposed underlying mechanism, there is evidence for an increased susceptibility to $\mathrm{SD}$ in migraine-susceptible brains in response to ischemia, which is known to exacerbate the metabolic mismatch and worsen stroke outcomes. ${ }^{66}$ Therefore, microembolic small vessel occlusions that remain completely unnoticed in the brains of non-migraineurs might cause SD in migraine-susceptible brains which leads to ischemic complications, including the development of WMLs.

\section{Neuroinflammation as a Possible Contributor to WMLs in Migraineurs}

The etiology of WMLs might not be identical to that of migraine-related strokes or WMLs in the elderly, and stroke typically does not develop as a continuum from WMLs. This is supported by the 9-year follow-up analysis of the CAMERA study, which shows that women with migraine have interval progression of their deep WMLs but do not exhibit increased territory infarct-like lesions/infarcts. ${ }^{8}$ Therefore, different mechanisms, at least in part, may underlie the development of WMLs versus infarcts in migraineurs. These factors might include local excessive neuronal activation, as well as neurogenic inflammation with neuropeptide and cytokine release.
Neurogenic inflammation has been well studied in migraine models and involves the release of vasoactive neuropeptides such as calcitonin gene-related peptide, pituitary adenylyl cyclase activating peptide, and substance $\mathrm{P}$ from trigeminovascular axons, protons (acid-sensing ion channels), cyclooxygenase-2-generating prostaglandins and other cyclooxygenase products, serine proteases, and nitric oxide (inducible nitric oxide synthase), as well as macrophages, dendritic cells, and mast cells. ${ }^{69}$ In fact, there is evidence for a proinflammatory baseline state in migraineurs, with increased peripheral levels of the proinflammatory cytokines IL- $1 \beta$, IL- 6 , and tumor necrosis factor- $\alpha$. Moreover, during a migraine attack, serum concentrations of $\mathrm{C}$-reactive protein, von Willebrand factor, IL-1 $\beta$, IL-6, IL-8, and tumor necrosis factor- $\alpha$ increase further. $^{70}$ There is evidence for intracranial plasma extravasation ipsilateral to the side of headache, with the demonstration of technetium- $99 \mathrm{~m}$ human serum albumin tracer extravasation in the area of reported pain, ${ }^{71}$ and gadolinium enhancement in close vicinity to the middle meningeal artery following a series of migraine attacks has been reported.

Neuroinflammation has been studied more extensively in multiple sclerosis. Glial activation in the white matter with increased glial uptake of the positron emission tomography ligand [11C]PBR28, a proxy for neuroinflammation, has been shown in patients with multiple sclerosis, in both normal-appearing white matter and WMLs. Higher levels of microglial activation are reportedly associated with a greater volume of subsequently enlarging lesions, ${ }^{73}$ suggesting that innate immune activation contributes to inflammatory neurodegeneration, confirmed by histopathologic analysis of WMLs in multiple sclerosis. ${ }^{74}$ Recent neuroimaging studies in migraineurs confirmed the importance of prolonged neuroinflammation during and after migraine attacks. Migraineurs exhibit an increased glial uptake of the same positron emission tomography TSPO-ligand [11C]PBR28, for at least 14 days after an attack. ${ }^{75}$ Interestingly, a strong, persistent extra-axial inflammatory signal was found in the meninges and calvarial bone overlying the occipital lobe in migraineurs during and after visual auras, implicating newly discovered bridging vessels that provide bidirectional crosstalk between the brain and skull marrow. ${ }^{76}$ A sustained signal in the calvarium may serve as a local repository of inflammatory cells and as a potential candidate to trigger subsequent attacks or possibly to promote migraine chronification.

\section{SD as a Possible Mechanism to Contribute to WMLs via both Neuroinflammation and Ischemia}

Neuroimaging studies suggest an important role for SD as the electrophysiological event underlying migraine attacks. The strongest evidence for a key role of SD in migraine aura 
comes from functional MRIs, with the demonstration of retinotopic congruence between the visual aura perception and SD-typical blood oxygen level-dependent signal changes traversing the occipital cortex. ${ }^{77}$ In addition, a typical sequence of speech and motor deficits characteristic of migraine aura have been observed in a patient with subarachnoid hemorrhage and electrocorticographic evidence for the occurrence of SD and SD-induced spreading depression of activity. ${ }^{78}$ Similarly, migraine aura symptoms have been described in patients with reversible cerebral vasoconstriction syndrome. SD is a self-propagating neuronal and glial depolarization wave that spreads at a speed of 2 to $9 \mathrm{~mm}$ per minute. ${ }^{79}$ In fact, transgenic mice carrying human familial hemiplegic migraine mutations are highly susceptible to developing SD upon weak stimuli and express migraine aura-like symptoms after SD, akin to patients with the respective mutations. ${ }^{80}$

These severe aura symptoms are associated with a facilitated spread of $\mathrm{SD},{ }^{81}$ which seems related to stronger synaptic connections. ${ }^{82} \mathrm{SD}$ can be triggered by neural disruption (Leão's hypothesis) ${ }^{55}$ or by vascular events (Wolff's hypothesis). For example, SD can be induced by embolic events, ${ }^{83}$ and even occlusion of a single cortical arteriole is sufficient to trigger $\mathrm{SD},{ }^{84}$ providing a candidate mechanism for SD induction in migraineurs, who seem prone to cerebrovascular clot formation and have an increased susceptibility to develop SD. ${ }^{85}$

$\mathrm{SD}$, induced by acute neuronal hyperexcitation, results in a cascade of events producing sterile inflammation in rodent models ${ }^{86,87}$ by triggering the release of proinflammatory prostaglandins and nitric oxide, while promoting mast cell degranulation, meningeal edema, and dilation of the middle meningeal artery as well as macrophage and dendritic cell activation. ${ }^{88}$ Cortical spreading depolarization leads to the opening and activation of pannexin 1 channels that release proinflammatory mediators and in turn induce cyclooxygenase- 2 and inducible nitric oxide synthase expression in astrocytes with microglial activation. Astrocytic release of cytokines, prostanoids, and nitric oxide into the subarachnoid space promotes sustained activation of trigeminal nerve fibers surrounding pial vessels and trigeminal nerve collaterals innervating the middle meningeal artery, thereby initiating neurogenic inflammation.

At the same time, in the healthy brain, SD stimulates the neurovascular unit to respond with marked vasodilatation and spreading hyperemia in the setting of normal neurovascular coupling to match increased neuronal energy demand. More specifically, single-photon emission computed tomography studies show a pattern of gradually spreading cortical hyperperfusion followed by gradual spreading hypoperfusion reminiscent of SD during a migraine aura. In contrast, during a migraine without an aura attack, there is no consistent evidence for a pattern of uniform vascular changes, although local changes have been shown, possibly due to neuronal activation. ${ }^{89}$ In fact, reversible MRI abnormalities that can be caused by SD have been observed during migraine aura, and they include regional cerebral vasogenic edema ${ }^{90}$ with evidence of vasogenic blood-brain barrier leakage in prolonged aura and an enhanced permeability of meningeal microvessels. ${ }^{54}$ It has been proposed that hyperperfusion and vasogenic leakage impair cortical function, leading to a delay in spontaneous recovery of neuronal suppression. It should be emphasized that, although SD typically propagates in gray matter, the hemodynamic consequences of SD also involve white matter, as previously confirmed with a near-infrared spectroscopy probe placed in the white matter of a patient with an aneurysmal subarachnoid hemorrhage. ${ }^{91}$ The correlation and complete resolution of both clinical and neuroimaging abnormalities suggest reversible changes/neuroinflammation in migraine with typical aura. Under pathologic conditions, the neurovascular unit may respond to SD with marked and prolonged vasoconstriction/spreading ischemia in the setting of inverse neurovascular coupling. ${ }^{55,92,93}$ These events may contribute to secondary neuronal injury in the migraineur's brain, with repetitive attacks causing cumulative injury, thereby contributing to the formation of WMLs (Figure 1).

In summary, migraine is a well-known independent risk factor for the development of subclinical, focal, deep WMLs early in the disease process, even in young and otherwise healthy individuals with no cardiovascular risk factors. Both ischemic and inflammatory mechanisms are proposed as underlying factors, as there is increased cerebral vulnerability to ischemia in migraineurs, as well as evidence for neuroinflammation during migraine attacks. $\mathrm{SD}$, the electrophysiological event underlying migraine, may be the mechanism that causes repetitive episodes of cerebral hypoperfusion and neuroinflammation during migraine attacks, possibly producing cumulative neuronal damage over time. In migraine-susceptible brains, both an increased susceptibility to SD and the enhanced consequences of SD may promote the development of WMLs.

\section{References}

1. Russell MB, Rasmussen BK, Thorvaldsen P, Olesen J: Prevalence and sex-ratio of the subtypes of migraine. Int J Epidemiol 1995, 24: 612-618

2. Kruit MC, Launer LJ, Ferrari MD, van Buchem MA: Infarcts in the posterior circulation territory in migraine. The population-based MRI CAMERA study. Brain 2005, 128:2068-2077

3. Bashir A, Lipton RB, Ashina S, Ashina M: Migraine and structural changes in the brain: a systematic review and meta-analysis. Neurology 2013, 81:1260-1268

4. Swartz RH, Kern RZ: Migraine is associated with magnetic resonance imaging white matter abnormalities: a meta-analysis. Arch Neurol 2004, 61:1366-1368

5. Zhang Q, Datta R, Detre JA, Cucchiara B: White matter lesion burden in migraine with aura may be associated with reduced cerebral blood flow. Cephalalgia 2017, 37:517-524 
6. Gaist D, Garde E, Blaabjerg M, Nielsen HH, Krøigård T, Østergaard K, Møller HS, Hjelmborg J, Madsen CG, Iversen P, Kyvik KO, Siebner HR, Ashina M: Migraine with aura and risk of silent brain infarcts and white matter hyperintensities: an MRI study. Brain 2016, 139:2015-2023

7. Hamedani AG, Rose KM, Peterlin BL, Mosley TH, Coker LH, Jack CR, Knopman DS, Alonso A, Gottesman RF: Migraine and white matter hyperintensities: the ARIC MRI Study. Neurology 2013, 81:1308-1313

8. Palm-Meinders IH, Koppen H, Terwindt GM, Launer LJ, Konishi J, Moonen JME, Bakkers JTN, Hofman PAM, van Lew B, Middelkoop HAM, van Buchem MA, Ferrari MD, Kruit MC: Structural brain changes in migraine. JAMA 2012, 308:1889-1897

9. Kurth T, Mohamed S, Maillard P, Zhu YC, Chabriat H, Mazoyer B, Bousser MG, Dufouil C, Tzourio C: Headache, migraine, and structural brain lesions and function: population based Epidemiology of Vascular Ageing-MRI study. BMJ 2011, 342:c7357

10. Kruit MC, van Buchem MA, Hofman PAM, Bakkers JTN, Terwindt GM, Ferrari MD, Launer LJ: Migraine as a risk factor for subclinical brain lesions. JAMA 2004, 291:427-434

11. Kruit MC, Launer LJ, Ferrari MD, van Buchem MA: Brain stem and cerebellar hyperintense lesions in migraine. Stroke 2006, 37: $1109-1112$

12. Porter A, Gladstone JP, Dodick DW: Migraine and white matter hyperintensities. Curr Pain Headache Rep 2005, 9:289-293

13. Longstreth WT Jr, Manolio TA, Arnold A, Burke GL, Bryan N, Jungreis CA, Enright PL, O'Leary D, Fried L: Clinical correlates of white matter findings on cranial magnetic resonance imaging of 3301 elderly people. The Cardiovascular Health Study. Stroke 1996, 27: $1274-1282$

14. Vermeer SE, Prins ND, den Heijer T, Hofman A, Koudstaal PJ, Breteler MM: Silent brain infarcts and the risk of dementia and cognitive decline. N Engl J Med 2003, 348:1215-1222

15. Vermeer SE, Hollander M, van Dijk EJ, Hofman A, Koudstaal PJ, Breteler MMB; Rotterdam Scan Study: Silent brain infarcts and white matter lesions increase stroke risk in the general population: the Rotterdam Scan Study. Stroke 2003, 34:1126-1129

16. Fazekas F, Kleinert R, Offenbacher H, Schmidt R, Kleinert G, Payer F, Radner H, Lechner H: Pathologic correlates of incidental MRI white matter signal hyperintensities. Neurology 1993, 43: $1683-1689$

17. Fernando MS, Simpson JE, Matthews F, Brayne C, Lewis CE, Barber R, Kalaria RN, Forster G, Esteves F, Wharton SB, Shaw PJ, O'Brien JT, Ince PG; MRC Cognitive Function and Ageing Neuropathology Study Group: White matter lesions in an unselected cohort of the elderly: molecular pathology suggests origin from chronic hypoperfusion injury. Stroke 2006, 37:1391-1398

18. Rostrup E, Gouw AA, Vrenken H, van Straaten ECW, Ropele S, Pantoni L, Inzitari D, Barkhof F, Waldemar G; LADIS study group: The spatial distribution of age-related white matter changes as a function of vascular risk factors-results from the LADIS study. Neuroimage 2012, 60:1597-1607

19. Eidlitz-Markus T, Zeharia A, Haimi-Cohen Y, Konen O: MRI white matter lesions in pediatric migraine. Cephalalgia 2013, 33:906-913

20. Mar S, Kelly JE, Isbell S, Aung WY, Lenox J, Prensky A: Prevalence of white matter lesions and stroke in children with migraine. Neurology 2013, 81:1387-1391

21. Kruit MC, van Buchem MA, Launer LJ, Terwindt GM, Ferrari MD: Migraine is associated with an increased risk of deep white matter lesions, subclinical posterior circulation infarcts and brain iron accumulation: the population-based MRI CAMERA Study. Cephalalgia 2010, 30:129-136

22. Erdélyi-Bótor S, Aradi M, Kamson DO, Kovács N, Perlaki G, Orsi G, Nagy SA, Schwarcz A, Dóczi T, Komoly S, Deli G, Trauninger A, Pfund Z: Changes of migraine-related white matter hyperintensities after 3 years: a longitudinal MRI study. Headache 2015, 55:55-70
23. Negm M, Housseini AM, Abdelfatah M, Asran A: Relation between migraine pattern and white matter hyperintensities in brain magnetic resonance imaging. Egypt J Neurol Psychiatr Neurosurg 2018, 54:24

24. van Veluw SJ, Zwanenburg JJ, Engelen-Lee J, Spliet WGM, Hendrikse J, Luijten PR, Biessels GJ: In vivo detection of cerebral cortical microinfarcts with high-resolution 7T MRI. J Cereb Blood Flow Metab 2013, 33:322-329

25. Kruit MC, Thijs RD, Ferrari MD, Launer LJ, van Buchem MA, van Dijk JG: Syncope and orthostatic intolerance increase risk of brain lesions in migraineurs and controls. Neurology 2013, 80:1958-1965

26. Rist PM, Dufouil C, Glymour MM, Tzourio C, Kurth T: Migraine and cognitive decline in the population-based EVA Study. Cephalalgia 2011, 31:1291-1300

27. Wen K, Nguyen NT, Hofman A, Ikram MA, Franco OH: Migraine is associated with better cognition in the middle-aged and elderly: the Rotterdam Study. Eur J Neurol 2016, 23:1510-1516

28. Baars MAE, van Boxtel MPJ, Jolles J: Migraine does not affect cognitive decline: results from the Maastricht aging study. Headache 2010, 50:176-184

29. Rist PM, Kang JH, Buring JE, Glymour MM, Grodstein F, Kurth T: Migraine and cognitive decline among women: prospective cohort study. BMJ 2012, 345:e5027

30. Xie H, Zhang Q, Huo K, Liu R, Jian ZJ, Bian YT, Li GL, Zhu D, Zhang LH, Yang J, Luo GG: Association of white matter hyperintensities with migraine features and prognosis. BMC Neurol 2018, 18:93

31. Sled JG, Pike GB: Quantitative imaging of magnetization transfer exchange and relaxation properties in vivo using MRI. Magn Reson Med 2001, 46:923-931

32. Schmierer K, Scaravilli F, Altmann DR, Barker GJ, Miller DH: Magnetization transfer ratio and myelin in postmortem multiple sclerosis brain. Ann Neurol 2004, 56:407-415

33. Granziera C, Daducci A, Romascano D, Roche A, Helms G, Krueger G, Hadjikhani N: Structural abnormalities in the thalamus of migraineurs with aura: a multiparametric study at $3 \mathrm{~T}$. Hum Brain Mapp 2014, 35:1461-1468

34. Granziera C, Romascano D, Daducci A, Roche A, Vincent M, Krueger G, Hadjikhani N: Migraineurs without aura show microstructural abnormalities in the cerebellum and frontal lobe. Cerebellum 2013, 12:812-818

35. Rocca MA, Colombo B, Pratesi A, Comi G, Filippi M: A magnetization transfer imaging study of the brain in patients with migraine. Neurology 2000, 54:507-509

36. Arkink EB, Palm-Meinders IH, Koppen H, Milles J, van Lew B, Launer LJ, Hofman PAM, Terwindt GM, van Buchem MA, Ferrari MD, Kruit MC: Microstructural white matter changes preceding white matter hyperintensities in migraine. Neurology 2019, 93:e688-e694

37. Yu D, Yuan K, Zhao L, Dong M, Liu P, Yang X, Liu J, Sun J, Zhou G, Xue T, Zhao L, Cheng P, Dong T, von Deneen KM, Qin W, Tian J: White matter integrity affected by depressive symptoms in migraine without aura: a tract-based spatial statistics study. NMR Biomed 2013, 26:1103-1112

38. Yuan K, Qin W, Liu P, Zhao L, Yu D, Zhao L, Dong M, Liu J, Yang X, von Deneen KM, Liang F, Tian J: Reduced fractional anisotropy of corpus callosum modulates inter-hemispheric resting state functional connectivity in migraine patients without aura. PLoS One 2012, 7:e45476

39. Rocca MA, Pagani E, Colombo B, Tortorella P, Falini A, Comi G, Filippi M: Selective diffusion changes of the visual pathways in patients with migraine: a 3-T tractography study. Cephalalgia 2008, 28:1061-1068

40. Chong CD, Schwedt TJ: Migraine affects white-matter tract integrity: a diffusion-tensor imaging study. Cephalalgia 2015, 35:1162-1171

41. Palm-Meinders IH, Arkink EB, Koppen H, Amlal S, Terwindt GM, Launer LJ, van Buchem MA, Ferrari MD, Kruit MC: Volumetric brain changes in migraineurs from the general population. Neurology 2017, 89:2066-2074 
42. Granziera C, DaSilva AFM, Snyder J, Tuch DS, Hadjikhani N: Anatomical alterations of the visual motion processing network in migraine with and without aura. PLos Med 2006, 3:e402

43. Colombo B, Dalla Libera D, Comi G: Brain white matter lesions in migraine: what's the meaning? Neurol Sci 2011, 32(Suppl 1): S37-S40

44. Sam K, Crawley AP, Conklin J, Poublanc J, Sobczyk O, Mandell DM, Venkatraghavan L, Duffin J, Fisher JA, Black SE, Mikulis DJ: Development of white matter hyperintensity is preceded by reduced cerebrovascular reactivity. Ann Neurol 2016, 80: 277-285

45. Woods RP, Iacoboni M, Mazziotta JC: Brief report: bilateral spreading cerebral hypoperfusion during spontaneous migraine headache. N Engl J Med 1994, 331:1689-1692

46. Olesen J, Friberg L, Olsen TS, Iversen HK, Lassen NA, Andersen AR, Karle A: Timing and topography of cerebral blood flow, aura, and headache during migraine attacks. Ann Neurol 1990, 28:791-798

47. Cutrer FM, Sorensen AG, Weisskoff RM, Ostergaard L, Sanchez del Rio M, Lee EJ, Rosen BR, Moskowitz MA: Perfusion-weighted imaging defects during spontaneous migrainous aura. Ann Neurol 1998, 43:25-31

48. Caplan LR, Hennerici M: Impaired clearance of emboli (washout) is an important link between hypoperfusion, embolism, and ischemic stroke. Arch Neurol 1998, 55:1475-1482

49. Erdélyi-Bótor S, Komáromy H, Kamson DO, Kovács N, Perlaki G, Orsi G, Molnár T, Illes Z, Nagy L, Kéki S, Deli G, Bosnyák E, Trauninger A, Pfund Z: Serum L-arginine and dimethylarginine levels in migraine patients with brain white matter lesions. Cephalalgia 2017, 37:571-580

50. Duvernoy H, Delon S, Vannson JL: The vascularization of the human cerebellar cortex. Brain Res Bull 1983, 11:419-480

51. Dalkara T, Nozari A, Moskowitz MA: Migraine aura pathophysiology: the role of blood vessels and microembolisation. Lancet Neurol 2010, 9:309-317

52. Uzar E, Evliyaoglu O, Toprak G, Acar A, Yucel Y, Calisir T, Cevik MU, Tasdemir N: Increased asymmetric dimethylarginine and nitric oxide levels in patients with migraine. J Headache Pain 2011, $12: 239-243$

53. Tietjen GE, Collins SA: Hypercoagulability and migraine. Headache 2018, 58:173-183

54. Sen S, Androulakis XM, Duda V, Alonso A, Chen LY, Soliman EZ, Magnani J, Trivedi T, Merchant AT, Gottesman RF, Rosamond WD: Migraine with visual aura is a risk factor for incident atrial fibrillation: a cohort study. Neurology 2018, 91:e2202-e2210

55. Dreier JP, Reiffurth C: The stroke-migraine depolarization continuum. Neuron 2015, 86:902-922

56. Hougaard A, Younis S, Iljazi A, Sugimoto K, Ayata C, Ashina M: Intravenous endothelin-1 infusion does not induce aura or headache in migraine patients with aura. Headache 2020, 60:724-734

57. Hougaard A, Younis S, Iljazi A, Haanes KA, Lindberg U, Vestergaard MB, Amin FM, Sugimoto K, Kruse LS, Ayata C, Ashina M: Cerebrovascular effects of endothelin-1 investigated using high-resolution magnetic resonance imaging in healthy volunteers. J Cereb Blood Flow Metab 2020, 40:1685-1694

58. Snijder RJ, Luermans JGLM, de Heij AH, Thijs V, Schonewille WJ, Van De Bruaene A, Swaans MJ, Budts WIHL, Post MC: Patent foramen ovale with atrial septal aneurysm is strongly associated with migraine with aura: a large observational study. J Am Heart Assoc 2016, 5:e003771

59. Lee MJ, Park BY, Cho S, Park H, Chung CS: Cerebrovascular reactivity as a determinant of deep white matter hyperintensities in migraine. Neurology 2019, 92:e342-e350

60. Tzourio C, El Amrani M, Poirier O, Nicaud V, Bousser MG, Alpérovitch A: Association between migraine and endothelin type A receptor (ETA -231 A/G) gene polymorphism. Neurology 2001, 56: $1273-1277$
61. Viola S, Viola P, Litterio P, Buongarzone MP, Fiorelli L: Stroke risk and migraine: near-infrared spectroscopy study. Neurol Sci 2012, 33(Suppl 1):S173-S175

62. Napoli R, Guardasole V, Zarra E, Matarazzo M, D'Anna C, Saccà F, Affuso F, Cittadini A, Carrieri PB, Saccà L: Vascular smooth muscle cell dysfunction in patients with migraine. Neurology 2009, 72: $2111-2114$

63. Cheng CY, Cheng HM, Chen SP, Chung CP, Lin YY, Hu HH, Chen CH, Wang SJ: White matter hyperintensities in migraine: clinical significance and central pulsatile hemodynamic correlates. Cephalalgia 2018, 38:1225-1236

64. Cadiot D, Longuet R, Bruneau B, Treguier C, Carsin-Vu A, Corouge I, Gomes C, Proisy M: Magnetic resonance imaging in children presenting migraine with aura: association of hypoperfusion detected by arterial spin labelling and vasospasm on MR angiography findings. Cephalalgia 2018, 38:949-958

65. Del Sette M, Dinia L, Bonzano L, Roccatagliata L, Finocchi C, Parodi RC, Sivori G, Gandolfo C: White matter lesions in migraine and right-to-left shunt: a conventional and diffusion MRI study. Cephalalgia 2008, 28:376-382

66. Eikermann-Haerter K, Lee JH, Yuzawa I, Liu CH, Zhou Z, Shin HK, Zheng Y, Qin T, Kurth T, Waeber C, Ferrari MD, van den Maagdenberg AMJM, Moskowitz MA, Ayata C: Migraine mutations increase stroke vulnerability by facilitating ischemic depolarizations. Circulation 2012, 125:335-345

67. Pezzini A, Busto G, Zedde M, Gamba M, Zini A, Poli L, Caria F, De Giuli V, Simone AM, Pascarella R, Padovani A, Padroni M, Gasparotti R, Colagrande S, Fainardi E: Vulnerability to infarction during cerebral ischemia in migraine sufferers. Stroke 2018, 49: $573-578$

68. Mawet J, Eikermann-Haerter K, Park KY, Helenius J, Daneshmand A, Pearlman L, Avery R, Negro A, Velioglu M, Arsava EM, Ay H, Ayata C: Sensitivity to acute cerebral ischemic injury in migraineurs: a retrospective case-control study. Neurology 2015, 85:1945-1949

69. Conti P, D’Ovidio C, Conti C, Gallenga CE, Lauritano D, Caraffa A, Kritas SK, Ronconi G: Progression in migraine: role of mast cells and pro-inflammatory and anti-inflammatory cytokines. Eur J Pharmacol 2019, 844:87-94

70. Torun E, Kahraman FU, Goksu AZ, Vahapoglu A, Cakin ZE: Serum catalase, thiol and myeloperoxidase levels in children passively exposed to cigarette smoke. Ital J Pediatr 2019, 45:59

71. Knotkova $\mathrm{H}$, Pappagallo $\mathrm{M}$ : Imaging intracranial plasma extravasation in a migraine patient: a case report. Pain Med 2007, 8:383-387

72. Arnold G, Reuter U, Kinze S, Wolf T, Einhäupl KM: Migraine with aura shows gadolinium enhancement which is reversed following prophylactic treatment. Cephalalgia 1998, 18:644-646

73. Datta G, Colasanti A, Rabiner EA, Gunn RN, Malik O, Ciccarelli O, Nicholas R, Van Vlierberghe E, Van Hecke W, Searle G, SantosRibeiro A, Matthews PM: Neuroinflammation and its relationship to changes in brain volume and white matter lesions in multiple sclerosis. Brain 2017, 140:2927-2938

74. Orsi G, Aradi M, Nagy SA, Perlaki G, Trauninger A, Bogner P, Janszky J, Illes Z, Dóczi T, Pfund Z, Schwarcz A: Differentiating white matter lesions in multiple sclerosis and migraine using monoexponential and biexponential diffusion measurements. J Magn Reson Imaging 2015, 41:676-683

75. Albrecht DS, Mainero C, Ichijo E, Ward N, Granziera C, Zürcher NR, Akeju O, Bonnier G, Price J, Hooker JM, Napadow V, Loggia ML, Hadjikhani N: Imaging of neuroinflammation in migraine with aura: a $\left[{ }^{11} \mathrm{C}\right] \mathrm{PBR} 28$ PET/MRI study. Neurology 2019, 92:e2038-e2050

76. Hadjikhani N, Albrecht DS, Mainero C, Ichijo E, Ward N, Granziera C, Zürcher NR, Akeju O, Bonnier G, Price J, Hooker JM, Napadow V, Nahrendorf M, Loggia ML, Moskowitz MA: Extra-axial inflammatory signal in parameninges in migraine with visual aura. Ann Neurol 2020, 87:939-949 
77. Hadjikhani N, Sanchez Del Rio M, Wu O, Schwartz D, Bakker D, Fischl B, Kwong KK, Cutrer FM, Rosen BR, Tootell RB, Sorensen AG, Moskowitz MA: Mechanisms of migraine aura revealed by functional MRI in human visual cortex. Proc Natl Acad Sci U S A 2001, 98:4687-4692

78. Major S, Huo S, Lemale CL, Siebert E, Milakara D, Woitzik J, Gertz K, Dreier JP: Direct electrophysiological evidence that spreading depolarization-induced spreading depression is the pathophysiological correlate of the migraine aura and a review of the spreading depolarization continuum of acute neuronal mass injury. Geroscience 2020, 42:57-80

79. Woitzik J, Hecht N, Pinczolits A, Sandow N, Major S, Winkler MKL, Weber-Carstens S, Dohmen C, Graf R, Strong AJ, Dreier JP, Vajkoczy P; COSBID study group: Propagation of cortical spreading depolarization in the human cortex after malignant stroke. Neurology 2013, 80:1095-1102

80. Eikermann-Haerter K, Dileköz E, Kudo C, Savitz SI, Waeber C, Baum MJ, Ferrari MD, van den Maagdenberg AMJM, Moskowitz MA, Ayata C: Genetic and hormonal factors modulate spreading depression and transient hemiparesis in mouse models of familial hemiplegic migraine type 1. J Clin Invest 2009, 119:99-109

81. Eikermann-Haerter K, Yuzawa I, Qin T, Wang Y, Baek K, Kim YR, Hoffmann U, Dilekoz E, Waeber C, Ferrari MD, van den Maagdenberg AM, Moskowitz MA, Ayata C: Enhanced subcortical spreading depression in familial hemiplegic migraine type 1 mutant mice. J Neurosci 2011, 31:5755-5763

82. Eikermann-Haerter $\mathrm{K}$, Arbel-Ornath $\mathrm{M}$, Yalcin N, Yu ES, Kuchibhotla KV, Yuzawa I, Hudry E, Willard CR, Climov M, Keles F, Belcher AM, Sengul B, Negro A, Rosen IA, Arreguin A, Ferrari MD, van den Maagdenberg AMJM, Bacskai BJ, Ayata C: Abnormal synaptic $\mathrm{Ca}\left(2^{+}\right)$homeostasis and morphology in cortical neurons of familial hemiplegic migraine type 1 mutant mice. Ann Neurol 2015, 78:193-210

83. Nozari A, Dilekoz E, Sukhotinsky I, Stein T, Eikermann-Haerter K, Liu C, Wang Y, Frosch MP, Waeber C, Ayata C, Moskowitz MA: Microemboli may link spreading depression, migraine aura, and patent foramen ovale. Ann Neurol 2010, 67:221-229

84. Dönmez-Demir B, Yemisci M, Kiliç K, Gürsoy-Özdemir Y, Söylemezoğlu F, Moskowitz M, Dalkara T: Microembolism of single cortical arterioles can induce spreading depression and ischemic injury; a potential trigger for migraine and related MRI lesions. Brain Res 2018, 1679:84-90

85. Ducros A: Reversible cerebral vasoconstriction syndrome. Lancet Neurol 2012, 11:906-917

86. Chen SP, Qin T, Seidel JL, Zheng Y, Eikermann M, Ferrari MD, van den Maagdenberg AMJM, Moskowitz MA, Ayata C, EikermannHaerter K: Inhibition of the P2X7-PANX1 complex suppresses spreading depolarization and neuroinflammation. Brain 2017, 140: $1643-1656$

87. Takizawa T, Qin T, Lopes de Morais A, Sugimoto K, Chung JY, Morsett L, Mulder I, Fischer P, Suzuki T, Anzabi M, Böhm M, Qu WS, Yanagisawa T, Hickman S, El Khoury J, Whalen MJ, Harriott AM, Chung DY, Ayata C: Non-invasively triggered spreading depolarizations induce a rapid pro-inflammatory response in cerebral cortex. J Cereb Blood Flow Metab 2020, 40:1117-1131

88. Zhang X, Levy D, Noseda R, Kainz V, Jakubowski M, Burstein R Activation of meningeal nociceptors by cortical spreading depression: implications for migraine with aura. J Neurosci 2010, 30: 8807-8814

89. Schytz HW, Amin FM, Selb J, Boas DA: Non-invasive methods for measuring vascular changes in neurovascular headaches. J Cereb Blood Flow Metab 2019, 39:633-649

90. Resnick S, Reyes-Iglesias Y, Carreras R, Villalobos E: Migraine with aura associated with reversible MRI abnormalities. Neurology 2006, 66:946-947

91. Seule M, Keller E, Unterberg A, Sakowitz O: The hemodynamic response of spreading depolarization observed by near infrared spectroscopy after aneurysmal subarachnoid hemorrhage. Neurocrit Care 2015, 23:108-112

92. Stanimirovic DB, Friedman A: Pathophysiology of the neurovascular unit: disease cause or consequence? J Cereb Blood Flow Metab 2012, 32:1207-1221

93. Dreier JP, Körner K, Ebert N, Gorner A, Rubin I, Back T, Lindauer U, Wolf T, Villringer A, Einhäupl KM, Lauritzen M, Dirnagl U: Nitric oxide scavenging by hemoglobin or nitric oxide synthase inhibition by N-nitro-L-arginine induces cortical spreading ischemia when $\mathrm{K}+$ is increased in the subarachnoid space. J Cereb Blood Flow Metab 1998, 18:978-990 